\title{
El ser como mediación. \\ Ontología, estética y analogía en la interpretación del 'esse' tomasiano de H. U. von Balthasar
}

\author{
Being as mediation. \\ Ontology, aesthetics and analogy in the interpre- \\ tation of H.U. von Balthasar of Thomasian 'esse'
}

\author{
Miquel SEGURÓ
}

Universidad Ramon Llull

Recibido: 28/09/2013

Aceptado: 29/09/2014

\section{Resumen}

El presente artículo expone los fundamentos de la interpretación que del esse tomasiano lleva a cabo Hans Urs von Balthasar. En ella ofrece von Balthasar, a partir de una interpretación en la línea de Siewerth, y como tal novedosa para la historia de la crítica, las directrices fundamentales de su propio pensamiento filosóficoteológico, cuyo eje lo constituye la diferencia entre esse y Dios como modelo para una hermenéutica no monista de la realidad. Con todo, la propuesta no está exenta de algunas dificultades y arbitrariedades que, desde una perspectiva crítica y aconfesional (por la que aquí se opta), conviene ineludiblemente subrayar.

Palabras clave: ser, diferencia, imagen, Dios, mundo.

\section{Abstract}

The present paper indicates the basic ways of the interpretation on the Aquinas esse of Hans Urs von Balthasar. As a principal vector of it von Balthasar follows the interpretation of Siewerth, offering us at the same time the foundations of his own philosophical-theological perspective, that central point is located in the difference among esse and God in a not monistic interpretation of the reality. However, from 
a critical and not confessional perspective his proposal contains some difficulties the arbitrariness that must be underlined

Keywords: being, difference, image, God, world.

\section{Introducción}

Hans Urs von Balthasar emerge a través de su magna y extensa obra como una de las figuras más destacadas y controvertidas de la reflexión filosófico-teológica del s. XX . Su proyecto filosófico, inseparable del teológico, gira en torno a las cuestiones más acuciantes de la existencia y pretende, desde su convicción cristiana, acometerlas. Su discurso, metodológicamente meta-antropológico ${ }^{1}$, se divide en tres grandes partes: una estética ${ }^{2}$, categoría decisiva de la estructura dinámica del ser o la 'forma'; una dramática', donde se narra el encuentro entre la libertad finita humana y la infinita divina, tan desemejantes como comunicativas; y una teológica ${ }^{4}$, desde la que piensa la verdad y su logos. Todo ello en base a los trascendentales (pulchrum, bonum, verum, unum $)^{5}$ y asumiendo como constante telón de fondo la cuestión más fundamental de todas, la del ser: si Dios no tiene necesidad del mundo, ¿por qué existe algo? 6

Para el intento de establecer una estética teológica, primer eslabón del proyecto, toma como eje conductor el estudio de la "Gloria" divina. Dentro de las muchas páginas que a ello le dedica, se detiene especialmente en el pensamiento de Tomás de Aquino, figura -central para él- con la que mantiene un fecundo diálogo y guarda cercana relación en sus posiciones. Porque von Balthasar no busca solamente reseñar históricamente las coordenadas de su pensamiento y dar con "el" pensamiento de Tomás (que también), si no que ante todo las interpreta a partir de la metafísica que él mismo elabora. Basándose en las investigaciones de su buen

\footnotetext{
1 Scola, A., Hans Urs von Balthasar: Uno stile teologico, Milano, Jaca Book SpA, 1991, pp. 47-48.

2 Herrlichkeit: eine Theologische Ästhetik,1961-1969 (trad.: Gloria. Una estética teológica. Madrid, Ed. Encuentro, 7 vols.).

3 Theodramatik, 1973-1983 (trad.: Teodramática. Madrid, Ed. Encuentro, 5 vols.).

4 Theologik, 1985-1987 (trad.: Teológica. Madrid, Ed. Encuentro, 3 vols., además de un Epílogo que concluye todo el proyecto).

5 „Gott kommt nicht primär als Lehrer für uns ('wahr'), als zweckvoller 'Erlöser' für uns ('gut'), sondern um Sich, das Herrliche seiner ewigen dreieinigen Liebe zu zeigen und zu verstrahlen, in jener Interesselosigkeit, die die wahre Liebe mit wahrer Schönheit gemein hat", decía en 1965 el propio von Balthasar respecto a su Herrlichkeit (Cf. Mein Werk. Durchblick, Einsiedeln, Johannes Verlag, 1990). Para la cuestión de los trascendentales en von Balthasar, cf. Infra, nota 35.

6 Para el propio von Balthasar esta es la pregunta más misteriosa y penetrante de toda la cuestión del ser [Cf. "Intento de resumir mi pensamiento", Communio, Revista Católica Internacional (ed. española), IV/88, p. 285]. Véase Coll, J.M., "Hans Urs von Balthasar (1905-1988)", p. 289, en Lluís Font, P. (ed.), 10 pensadors cristians del s. XX. Barcelona, Ed. Cruïlla, 1999.
} 
amigo Gustav Siewerth ${ }^{7}$, sitúa el ser en la filosofía tomasiana de un modo diferente a la tradicional interpretación dada a su ontología y sonsaca a partir de ahí las consecuencias que a su juicio comporta asumir la tesis leimotiv de Siewerth: el "ser" como mediación entre lo finito y lo in-finito.

En este artículo buscamos reseñar y discutir lo que nos dice von Balthasar al respecto, no solo por la relevancia que supone para la interpretación de la filosofía tomasiana, sino también porque en ella hallamos muchas claves de su propio itinerario reflexivo que nos ayudará a calibrar el alcance último de su propuesta de analogía del ser que, como veremos, no está exenta de excesos. El desarrollo de nuestra aproximación será en primer lugar expositivo. Daremos la palabra a nuestro autor para tratar de comprender sus posiciones con el fin de poder trazar, después, algunas pinceladas críticas que, si bien requerirán de un mayor y más profundo estudio, por lo menos nos permitirán vislumbrar la tesis de fondo que queremos poner sobre la mesa: la supuesta superación de la metafísica antropológica o trascendental propuesta por von Balthasar supone volver de algún modo a la filosofía pre-crítica y, por lo tanto, a los excesos de la metafísica dogmática. Para ello deberemos asumir como natural contexto de debate la disputa que en torno a la analogía y su valor (analogia entis vs analogia fidei) tuvo lugar a lo largo de la primera parte del siglo pasado, y en el cual von Balthasar participó activamente. Aunque lejos de darle la razón a alguna de las partes implicadas, aquí nos empuja la necesidad de recordar la irremediable finitud con la que debemos asumir el modo de relacionarnos con las cuestiones metafísicas y, de ahí, entender la analogía como hermenéutica existencial hecha desde la contingencia y la finitud. No es, ciertamente, nada nuevo; Kant o Jaspers han dicho mucho sobre ello. Pero en todo caso no está de más recordarlo a la luz de algunas arbitrariedades meta-físicas que superan las capacidades de la racionalidad, provengan estas de la analogia entis o de la analogia fidei.

\section{La ontología estética de Tomás de Aquino}

\subsection{La belleza y el ser}

"La doctrina tomista de la distinción entre esse y essentia es una fórmula filosófica; pero permite por primera vez separar claramente la 'gloria' de Dios de la belleza cósmica". Esto implica asumir que "Santo Tomás ve al hombre, capacitado para pensar el ser, en una particular oscilación entre lo natural y lo sobrenatural"9.

\footnotetext{
7 Pérez Haro, E., El misterio del ser. Una mediación entre Filosofia y Teología en Hans Urs von Balthasar, Barcelona, Santandreu Ed., 1994, p. 135.

8 V. Balthasar, Gloria, vol. 4. Metafisica, Edad Antigua, Madrid, Ed. Encuentro, 1986, p. 355 (orig.: „Thomas'Lehre von der Realdistinktion zwischen esse und essentia ist ein philosophischer Satz; aber
} 
A partir de estas dos afirmaciones busca poner de manifiesto nuestro autor la centralidad vertebradora que tiene la "diferencia" en la filosofía de Tomás, hasta el punto que puede decir que su olvido impide una plena comprensión de su filosofía. Es más: para von Balthasar el reconocimiento de la diferencia permite situar la filosofía, en general, en un nuevo kairós que le brinda la oportunidad de superar las aporías derivadas del pensamiento monista (mundo griego y cristiano) en lo relativo al dilema de la realidad "creada", finita, y su (in)consistencia metafísica.

El papel central otorgado a la diferencia afecta en primer lugar la relación entre la filosofía y la teología10. Para von Balthasar la filosofía y la teología mantienen una intrínseca relación constitutiva, de manera que la una sin la otra queda huérfana de compañera de "peregrinaje". Así, la teología requiere de la filosofía porque sin ella se ve reducida a una ciencia positivista de los hechos de la "Revelación" divina (cristiana); y a su vez, toda filosofía está bajo el influjo de la "Revelación", en el sentido que siempre estamos en relación (positiva o negativa) con el Dios de Jesucristo, de modo que la relación neutra con la naturaleza no existe, y dado que el polo de lo sobrenatural, si bien contrapuesto, está siempre presente en ella, según concibamos la naturaleza co-afirmaremos nuestra posición frente a dicho sobrenatural. De ahí que todo sujeto esté bajo el influjo del apriori teológico de la luz de la fe (Cristo como testimonio del amor de Dios, dice), y por ello, no existe una filosofía, en tanto que reflexión de ese sujeto, pura y neutral11.

Esta radicalidad de partida no impide que la metafísica quiera ir por su cuenta, aunque precisamente por estar exclusivamente centrada en la "creación" pierda de vista el plano de su origen y fin último hasta el punto de des-ligarse de él, y que no es otro que el plano de la "gracia"12. La cuestión de fondo a plantearse es para von Balthasar clara: "¿llamada espiritual desde la profundidad del ser, o proyección de la personalidad humana en el ser impersonal?"13. Por eso para von Balthasar no supone ningún problema que la teología, en tanto que lo sobrenatural, disuelva en sí el pensar científico y filosófico, lo natural, puesto que comparte con esta el punto

er erlaubt erstmals wieder, die 'Herrlichkeit' Gottes von der kosmischen Schönheit klar zu trennen", Herrlichkeit. Im Raum der Metaphysik (Band 3/1), Einsiedeln, Johannes Verlag, 1965, p. 356).

9 Ídem. (orig.: ,dass den Menschen, dem das Sein zu bedenken gegeben ist, in einer eigentümlichen Schwebe zwischen Natur und Übernatur sieht", Ídem).

10 Ibíd. pp. 355-356 (orig.: Herrlichkeit, op. cit., pp. 356-357).

11 Albus, Michael, Die Wahrheit ist Liebe. Zur Unterscheidung des Christlichen nach Hans Urs von Balthasar, Freiburg-Basel-Wien, Herder, 1976, p. 31.

12 Se refiere von Balthasar a "...la palabra de la revelación divina, la cual ahora, por fin, revela el fundamento de por qué el ser anuncia la gracia y de dónde procede el poder ser" [Gloria, vol 5. Metafísica. Edad moderna, Madrid, Ed. Encuentro, 1988, p. 582] (orig.: „das Offenbarungswort Gottes sich ermöglicht, das nun erst den Grund dafür offenbart, warum Sein von Gnade kündet, und woher das Seinsdürfen stammt", Herrlichkeit, op. cit., p. 963).

13 Ibíd., p. 578 (orig.: „geisthafter Anruf aus der Seinstiefe -oder Projektion der menschlichen Personalität in das inpersönliche Sein?", Ibíd., p. 959). 
de partida: ambas giran en torno a la diferencia ontológica entre el ser y el ente, diferencia que es la fuente de todo el pensamiento religioso de la humanidad. Las aporías de la reflexión filosófica se resuelven así en una teológica del ser, de modo que solo desde la "Revelación", subraya von Balthasar, se nos permite decidir en favor del ser como gloria y amor, allende los aspectos más terribles y oscuros de la existencia ${ }^{14}$.

Establecida la cuestión desde esta radicalidad fundamental, prosigue von Balthasar buscando los fundamentos del pensar tomasiano en la herencia recibida del Pseudo-Dionisio, Agustín de Hipona y Aristóteles. De dichas referencias surge la concepción de la belleza como "debita proportio sive consonantia", donde proportio es lo mismo que harmonia, conformitas, apunta (la claritas, por el contrario, ostenta un valor más afianzado en sí misma). La estrecha relación que se establece entre la forma y la belleza se delata, por ejemplo, en los escritos de juventud de Tomás, en los que detecta, por otro lado, la notoria influencia de Alberto Magno15. Este dato es de vital importancia no solo para el establecimiento de unas coordenadas histórico-críticas de la obra del Aquinate, sino que para von Balthasar ante todo nos abre a un (re)planteamiento de los 'atributos' del ser, o lo que es lo mismo, a la intrínseca relación que guardan entre sí los trascendentales.

No podemos desarrollar aquí en toda su complejidad esta cuestión porque requeriría de una investigación en paralelo y una atención específica que supera el anhelo de este artículo, como así lo demuestran las profundas páginas que a ello se han dedicado ${ }^{16}$. Sí cabe apuntar, empero, que para von Balthasar el Aquinate sitúa preeminentemente el 'Pulchrum' sobre el 'Verum' y el 'Bonum'. Aunque se suponga una unidad fundamental entre Bien y Belleza (Pseudo-Dionisio) -en efecto afirmada por el Aquinate- no se excluye al mismo tiempo una diferenciación conceptualmente radical, ya que solamente desde esa independencia se explica, por ejemplo, cómo también la Belleza puede ser aproximada a la Verdad (Alejandro de Hales, Alberto Magno), o que sea posible reconocer la no-homogeneidad de su unidad atributiva en relación al Bonum, pues si bien el Bien (valga la redundancia) es el fin a alcanzar, la Belleza es admirada y amada por su forma más allá de su finalidad 17 .

\footnotetext{
14 Pérez Haro, E., El misterio del ser..., op. cit., pp. 64-75.

15 V. Balthasar, Gloria. Vol 4, op. cit., pp. 356-358 (orig.: Herrlichkeit, op. cit., pp. 357-359). Todas estas y demás influencias quedan bien glosadas según resalta von Balthasar en el pasaje I d31, 2, 1 del Comentario a las Sentencias.

16 Por ejemplo, las de Paul Gilbert en "L'articulation des transcendantaux selon Hans Urs von Balthasar", Revue Thomiste, 86 (1986), pp. 616-629.

17 V. Balthasar, Gloria. Vol 4, op. cit., p. 359 (orig.: Ibíd., p. 360). Para una breve ponderación histórico-sistemática de la cuestión en von Balthasar, cf. Infra, nota 35.
} 


\subsection{El ser como semejanza de Dios}

Centrado ya en el Pulchrum, lo primero que subraya von Balthasar es que la teoría de la belleza del Aquinate es sinuosa. Transita de unas categorías más aristotélicas y sobrias a otras más platónicas y dinámicas. De hecho, de la influencia de esta última tradición extrae la doctrina del ser como primera e inmediata acción de Dios en el mundo (Pseudo-Dionisio)18: el ser es lo comunissimum al tiempo que es lo intimum quid profundum omnibus inest. Es lo inagotable por cualquier número de naturalezas y siempre participable infinitamente, aunque solo realiza a dichas naturalezas realizándose al mismo tiempo en ellas. Por eso debe extraerse que no tiene subsistencia en sí mismo, dice von Balthasar: al ser la subsistencia inherente a dichas naturalezas, el esse es no-subsistens. Veámoslo con mayor detenimiento.

En el De Potentia sostiene Tomás, en efecto, que "esse non est subsistens sed inhaerens"19; y anteriormente también que "esse significat aliquid completum et simplex sed non subsistens" 20 . La claridad del Aquinate parece meridiana en este punto. Sin embargo, y aunque ciertamente el esse subsista a través del ente, esta afirmación ontológica no conlleva asumir que las naturalezas son meras posibilidades emancipadas, apunta von Balthasar. Las formas son "quaedam sigillatio divinae scientiae in rebus" 21 , por eso solamente el intelecto divino es capaz de inventarlas y ponerlas (darlas) 22 . A su vez, la criatura no se entiende como desintegración ni fracción del ser divino, sino como signo positivo del fundante amor de lo Absoluto. Por ello, en la finitud intrínseca de la criatura se revela la diferencia total y radical con Dios - dicho Absoluto-, que le regala la participación en el ser real y efectivo. Este esse es para Tomás, según von Balthasar, "lo más noble, el efecto primero y más peculiar de Dios, porque 'Dios con el ser produce las cosas', y el 'ser es anterior y más íntimo que todos los demás productos'; y vacio, porque no existe como tal, pues 'si no se puede decir que el correr corre, sino el corredor', 'tampoco se puede decir que el ser es "'23. El ser no es propiamente subsistente y por ello no se solidifica ni identifica con Dios (idealismo panteísta).

${ }^{18}$ La atención que Balthasar dedicó a los Padres de la Iglesia explica muchas de sus propias intuiciones. De todos ellas, destaca la prestada a Gregoria de Niza, y en concreto la imposibilidad última de concebir el ser que su obra postula, pues solo desde ahí es posible mantener que Dios sea el Ser, precisamente en tanto que Presencia inagotable e inaprehensible. (Ide, P., Etre et Mystère. La philosophie de Hans Urs von Balthasar. Bruxelles, Culture et Vérité, 1995, pp. 140-150).

19 De Pot., 7, 2, ad 7.

20 De Pot., $1,1$.

21 De Ver., 2, 1, ad 6.

22 V. Balthasar, Gloria. Vol 4, op. cit., pp. 359-361 (orig.: Herrlichkeit, op. cit., pp. 360-363).

23 Ibíd., p. 362 (orig.: „es das Edelste ist, die erste und eigentlichste Wirkung Gottes, weil 'Gott durh das eina lles verursacht', und 'das Sein früher und innerlicher ist als alle übrigen Wirkungen, Nichtichkeit aber, da es als solches nicht existiert, 'denn wie mann nicht sagen kann, dass das Laufen läuft', sondern der Laufende, so kann man 'auch nicht sagen, dass das Sein ist’, Ibíd., pp. 363-364). 
Para von Balthasar "la diferencia ontológica entre ser y esencia encuentra su razón de ser en la relación que surge entre el participado y el partícipe, lo que permite hablar de una 'participación de la no-participación'"24. Por eso podemos hablar de una real referencia ontológica de cada ente al ser pleno (participación) sin que ello obligue a lo divino a mezclarse con lo creado (im-participación). Se trata esta de una dialéctica que para nuestro autor tiene como hilo conductor la necesidad de evitar toda forma de racionalización o esencialización del ser que destruya su misterio suprarracional y supraesencial, pues se destruiría la "imagen y semejanza" divina que se trasluce en el ser.

En otras palabras, lo que pretende von Balthasar es defender la actualidad del ser más allá de la concreción entitativa que supone la existencia del "mundo". ¿Pero de qué actualidad nos está hablando?

Von Balthasar no se conforma solamente con recuperar la actualidad "desnuda" del ser, sino que da un paso más e intensifica ese actus asumiéndolo como similitudo Dei. Pensemos en el hombre, dice, cuya "fracción del ser en el ente" (participación) que es se auto-trasciende y queda como suspendida, tanto formal como ontológicamente, frente al Dios libre, convirtiéndose así en la semejanza indicativa, mediata, de la bondad divina ${ }^{25}$. Ahora bien, que el hombre es finito es de obligado reconocimiento, e incluso que desde esa finitud proyecta su interpretación del mundo. Pero que esa finitud pone necesariamente un infinito que responde arquetípicamente a su imagen y que por eso es su semejanza es más discutible. De hecho parece más bien lo contrario. Dependerá en todo caso de los aprioris antropológicos y epistemológicos que dicho planteamiento atributivo comporte. Y es que ahí está el quid de la cuestión: si no se quiere caer en la arbitrariedad metafísica habría que afinar mucho el alcance, quizás de índole más bien simbólico (y por el lado más antropológico, justo lo que von Balthasar no aceptaría) de semejantes afirmaciones atributivas.

\subsection{La metafisica como estética}

Pero dejemos los análisis para un poco más adelante y volvamos a von Balthasar. Puesto que la actualidad del ser se concreta en las esencias, la estética (recordémoslo, "Herrlichkeit", Gloria, en tanto que belleza) entendida como "medida, número y peso" tendrá su razón de ser no en la esencia abstracta sino en la real, es decir, actualizada. Y puesto que lo que pretende nuestro autor es superar el "peligro" del monismo eidético, añade que siempre hay que puntualizar que la realización última de esas esencias radica en una máxima realidad que las trasciende, desde las cuales pueden ser estas pensadas. ¿Unívocamente? En este punto clave

\footnotetext{
24 Luciani Rivero, Rafael Francisco, El misterio de la diferencia : un estudio tipológico de la analogía como estructura originaria de la realidad en Tomás de Aquino, Erich Przywara y Hans Urs von Balthasar y su uso en teología trinitaria, Roma, PUG, 2002, p. 296.

25 V. Balthasar, Gloria. Vol 4, p. 364 (orig.: Herrlichkeit, op. cit., p. 365-366).
} 
puntualiza von Balthasar que la asunción que Tomás hace de la metafísica estética de Dionisio lo despoja de toda sospecha panteísta, pues la mediación del ser le permite tender un puente entre Dios y criatura ${ }^{26}$. Que Dionisio no lo dijera exactamente así no significa que sea erróneo sonsacar esta conclusión; más bien significa para von Balthasar que dejó a medio camino la interpretación propia de ese ser primeramente "emanado" 27.

La criatura, proporción entre ser y esencia, establece una relación estructural interna que a su vez se relaciona, en tanto que unidad, con su fundamento último que es Dios. Esta "relación de relación" es la que nos permite pensar "estéticamente" con conceptos relativos del tipo proportionalitas o dispositio, por que allí donde domina el fundamento, hay orden, apunta. Un orden que es a la vez inmanente y trascendente. Todas las partes del universo están acordes unas con otras y su fundamento último corona el edificio ontológico del que forman parte. Por ello, se permite recomendar von Balthasar a la ciencia de hoy acudir a la filosofía del Aquinate para hallar la manera de no absolutizar las leyes que componen ese orden, y sopesar desde ahí la proporción entre ser y esencia de la criatura con su fundamento libre -el Dios cristiano- permitiendo así dotar de sentido trascendente la "relación de relación" antes mencionada 28 . Una aseveración del todo sorprendente (esta última) porque, además de poner en tela de juicio mucho de la cosmología y física teórica actuales, comporta de buenas a primera la restauración de un realismo que a los ojos de la crítica kantiana, las deconstrucciones de la posmodernidad y las hermenéuticas modales carece de cualquier viabilidad epistemológica.

Así pues, las breves pinceladas aquí trazadas nos permiten dibujar una interpretación balthasariana de la metafísica-estética de Tomás de Aquino tan sugerente como repleta de elementos metafísicos a considerar y calibrar. Un sistema metafísico que es para von Balthasar de primera referencia porque "la metafisica de Santo Tomás es el reflejo filosófico de la libre gloria del Dios vivo de la Biblia y, con ello, la consumación intrínseca de la filosofía antigua (y por lo tanto la humana). Es un canto de alabanza a la realidad de lo real, al misterio del ser que todo lo abarca, que supera todo lo pensable, que está henchido del misterio mismo de Dios, y en el que las criaturas pueden participar de la realidad divina, dado que al ser lo alumbra en su vaciedad e insubsistencia la libertad del fundamento creador como amor sin fondo"'29.

\footnotetext{
26 En efecto, dice Pseudo Dionisio en De Divinis Nominibus, 824-A: "No es un aspecto del ser; el ser es una faceta de Él. No está contenido en el ser, sino que Él contiene al ser. Él es la eternidad del ser, origen y medida del ser. El es anterior a la esencia, a la existencia y a la eternidad" (según se traduce en la edición de Martín-Lunas, Madrid, BAC, $1995^{2}$. El subrayado es nuestro).

27 V. Balthasar, Gloria. Vol 4., op. cit., pp. 364-365 (orig.: Herrlichkeit, op. cit., pp. 366-367).

28 Ibíd., pp. 366-368 (orig.: Ibíd., pp. 368-369).

29 Ibíd., p. 364 [orig.: „Thoma's Metaphysik ist somit die philosophische Widerspiegelung der freien Herrlichkeit des lebendigen Gottes der Bibel, und darin die innere Vollendung der antiken (und damit
} 


\section{La diferencia entre 'ser' y 'Dios' como ontología teológica}

Como apuntamos en la "Introducción", von Balthasar se apoya en las tesis de Gustav Siewerth para no identificar el ser con Dios. Y a la luz de lo expuesto se entiende que diga del Aquinate, asumiéndolo también para sí, que "habiendo concebido Tomás el esse como la no-subsistente plenitud y perfección de toda realidad y como máxima 'semejanza de la divina bondad', y no pudiendo, en consecuencia, ser y a nunca más designado Dios como el ser de las cosas, salvo como su causa eficiente, ejemplar y final, Dios es alejado, de un modo nuevo y mucho más radical, más allá, y encima de todo ser del mundo"30.

El asombro del ser, que para von Balthasar constituye el punto de partida radical de la experiencia existencial, no es un momento aislado del ejercicio filosófico. De hecho, el "milagro radical" que es el ser debería ser el tema constante de la metafísica ${ }^{31}$. Solo desde la asunción de este reconocimiento es posible pretender desvelar la "gloria" que viene ulteriormente dada por el reconocimiento del orden. Pero esta halla su descanso en algo que nos trasciende totalmente (el ser primero), luego el desvelo "glorioso" tendrá que venir dado a través de la diferencia con lo mundano. Para von Balthasar la diferencia tiene una cuádruple faz: la diferencia óntica, la diferencia ontológica, la diferencia entre ser y Dios, y la diferencia entre Dios y mundo 32 . Ciertamente toda experiencia pasa por el "mundo". Por eso una reducción total del ser al "ser del ente" comporta que este aparezca como algo extraño y casi terrible, de modo que sintamos la necesidad de aprehenderlo como algo sin valor. Para von Balthasar el ser "del mundo" es portador de la "gloria".

Conviene aquí aclarar que nuestro autor prefiere no usar de la categoría "expresión' por connotar algo simbólico, aunque no por ostentar esta un sentido peyorativo. De hecho, entiende que lo simbólico sería de por sí suficientemente explícito para darnos el sentido de algo que sobrepasa todo orden mundano y cualquier sublime belleza. Pero en un sentido más trascendente que trascendental, porque la clave

menschheitlichen) Philosophie. Sie ist ein Preislied auf die Wirklichkeit des Wircklichen, auf jenes alles umgrefeinde, jede Ausdenkbarkeit überragende Geheimnis des Seins, schwanger vom Gottgeheimnis selbst, in dem die Geschöpfe an Gottes Wirklichkeit teilnehmen dürfen, und das doch, in seiner Nichtigkeit und Nichtsubsistenz durchleuchtet ist von der Freiheit des schaffenden Grundes als grundloser Liebe", Ibíd., p. 366].

30 Ibíd, pp. 353-354 (orig.: „Indem aber Thomas das 'Esse' als die nichtsubsistierende Fülle und Vollkommenheit alles Wirklichen und als höchstes 'Gleichnis göttlichen Gutseins'versteht, und damit Gott keinesfalls mehr als das Sein der Dinge bezeichnet werden kann, es sei denn als deren Wirk-, Exemplar- und Zielursache, wird Gott auf neue viel radikalere Weise über alles Weltsein", Ibíd., p. $354)$.

31 Gloria, vol 5., op. cit., p. 564 (orig.: Herrlichkeit, op. cit., p. 944).

32 Ibíd., pp. 565-575 (orig.: Ibíd., pp. 945- 957). El tema queda magníficamente desarrollado en Pérez Haro, E., El misterio del ser.., op. cit., pp. 102-214; también en Coll, J.M., "Hans Urs von Balthasar", op. cit., pp. 292-294. 
reside en el valor otorgado a la diferencia y al polo al que se le da la preeminencia: el signo que simboliza o la referencia simbolizada. De ahí que von Balthasar prefiera un modelo meta-físico más "objetivo" donde el punto de partida para pensar "la" realidad sea la diferencia comprendida como punto de encuentro. Si el método de afirmación asciende desde lo ente hasta lo divino, la diferencia que lo posibilita solamente cobra valor porque Dios la asume en su interioridad. Es decir, la diferencia entre ser y ente adviene tras asumir la diferencia entre Dios y mundo, y sobre todo entre Dios y ser. Así, Dios se revela como el fundamento absoluto y suficiente tanto para el ser como para el ente, de ahí que afirme que la libertad del ser nosubsistente solo encuentra su fundamento en la libertad absoluta subsistente, a través de la cual se garantiza a sí misma como su "gloria"33.

Entonces: ¿estamos ante un sistema cerrado auto-referenciado donde Dios se comporta como un Absoluto holístico formal y ontológico? ¿O por el contrario la diferencia entre el ser subsistente y no-subsistente nos aboca precisamente a una distancia de esferas casi incomunicable?

El ser no es Dios [onto(teo)logía] ${ }^{34}$, como tampoco es ningún ente particular ni hipóstasis alguna. Podríamos entonces pensar que es una abstracción conceptual que roza lo formal. Pero tampoco: es algo supraconceptual, que no responde a ningún objeto, sino que posibilita el conocimiento de estos. Para von Balthasar no todo puede ser delimitación negativa, ya que paralelamente emerge con potencia una intensificación (como diría C. Fabro) positiva del mismo. Y es que el ser lo concibe como plenitud, cuya riqueza se despliega en los trascendentales: unidad, verdad, bondad y belleza ${ }^{35}$. Por eso mismo el ser es, fundamentalmente, simplicidad, de

33 Ibíd., pp. 568-574 (orig.: Ibíd., pp. 949-956).

34 Resuena la voz de Heidegger. Recordemos que en este la crítica a la onto(teo)logía comporta la denuncia de Dios como Causa Sui ("el dios de los filósofos"), frente al cual el hombre en ningún caso puede rezar ni postrarse. Por eso toda pretensión de rescatar lo divino debería pasar necesariamente por la destitución de dicha onto(teo)logía en la reflexión metafísica. (Cfr. Identidad y Diferencia, Barcelona, Anthropos Ed., 1990, p. 153).

35 Pérez Haro, E., El misterio del ser..., op. cit., pp. 136-139. Para una visión general, son muy valiosos tanto el artículo de Paul Gilbert citado, "L'articulation des transcendantaux selon Hans Urs von Balthasar" [Revue Thomiste, 86 (1986) 616-629], como la síntesis que realiza Martin Bieler en su Freiheit als Gabe. Ein schöpfungstheologischer Entwurf (Freiburg, Herder, 1991, pp. 458-463).

Es interesante notar el modo en que aborda von Balthasar la cuestión de los universales en las obras finales de su trayecto metafísico ("Intento de..." art. cit, p.286). Generalmente su obra trabaja explícitamente el Pulchrum, el Bonum y el Verum (Gloria, Teodramática y Teológica), sin embargo no dedica al Unum un análisis específico. Josep Maria Coll afirma ("Hans Urs von Balthasar", op. cit, p. 294) que quizás ello se deba a que este último esté implícito en toda la obra Triádica de von Balthasar. En todo caso, lo cierto es que el Unum es en "Intento de..." el punto de partida de la experiencia del infante y no el corolario final del proceso de descubrimiento del Ser como podría parecer siguiendo el orden balthasariano de los trascendentales. Este lugar lo reserva en el mencionado texto para el Pulchrum, cuando precisamente es dicho trascendental el que inicia toda su trilogía (Gloria), desvelándose el resto a partir de este (Scola, A., Hans Urs von Balthasar..., op. cit., pp. 43-44). Si la epifa- 
modo que para von Balthasar puede decirse muy a la hegeliana que se asemeja a su contrario: la nada. Es más, el ser es ciertamente plenitud, pero atravesada por la nada, pues esta, en tanto que es aquella realidad única que ninguna cosa es, se acerca al ser en tanto que no subsiste, es decir, en tanto que es "la anulación de la plenitud participada del ser en su no-subsistencia"36. Comparten, por decirlo de algún modo, pureza.

Ahora bien, si el ser es mediación entre Dios y las cosas, y los entes vienen a la subsistencia a través de este ser que resulta no ser subsistente en sí mismo, ¿cómo se explica la subsistencia? ¿Es algo previo, añadido o consecuente al ser? Von Balthasar responde que por el hecho que Dios está íntimamente ligado a las cosas más allá de la mediación del ser. Dios, como forma de las formas del ser subsistente, es el fundamento de todo (ser mundano) y está inmanentemente en todo. Así, el ser es mediación de subsistencia sin que el mismo lo sea, precisamente para permitir tal acto de mediación, que desaparecería con cualquier consolidación hipostáti-

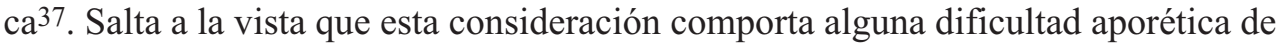
difícil superación, pero por ahora quedémonos con que frente a la identificación irremediablemente panteísta y de necesidad de acción que implica la identidad de Dios y el ser, con el ser como mediación cree von Balthasar poder explicar tanto la libertad de Dios en su acto de creación como la libertad de la criatura en su decisión amorosa para con su Creador. De esta forma el ser entendido como mediación no subsiste ni es personal, y por ello parece plausible interpretarlo como "lo" divino, como un fluido transitar a través y más allá de las realidades concretas. El ser subsistente es "Revelación" de aquel de quien es semejanza, y por eso de alguna manera palabra, símbolo primordial que no agota todo el lenguaje sobre "lo divino", ciertamente, pero que permite acoger en su estructura la "palabra hecha carne" -última palabra divina. Para von Balthasar el ser subsistente como "gloria" es la estructura que explica y prepara la Encarnación. 38

Vemos, pues, como esta interpretación del ser como mediación queda profundizada y enriquecida en su formulación en la (co)siguiente comprensión, también siewerthiana, del ser como semejanza de Dios (Das Sein als Gleichnis Gottes) ${ }^{39}$. Una

\footnotetext{
nía del ser arranca en el pulchrum, e incluso en la misma raíz del amor divino hay que colocar la raíz estética [Herrlichkeit -"gloria"-, como así lo especifica en su Glaubhaft ist nur Liebe (Einsiedeln, Johannes Verlag, $1975^{2}$, p. 36)] ¿por qué aquí von Balthasar cambia el orden y no sitúa al principio la unicidad del ser en el punto de partida, cerrando el círculo de su desvelo el pulchrum? Y más todavía, si el unum está en la base de toda su trilogía, y es así su a priori, ¿por qué no le sigue en este texto el pulchrum en vez del bonum?

36 V. Balthasar, Gloria, vol. 5, op. cit., p. 578 (orig.: „,das Nichten der mit geteilten Seinsfülle in ihrer Nichtsubsistenz", Herrlichkeit, op. cit., p. 958).

37 Pérez Haro, E., El misterio del ser..., op. cit., pp. 141-149.

38 Ibíd, pp. 185-191.

39 Siewerth, G., Das Sein als Gleichnis Gottes, Heidelberg, F. H. Kerle, 1958, pp. 24-29, pp. 41-49, pp. 54-57, pp. $65-81$.
} 
semejanza que, sin embargo, asume a la vez la necesaria teología negativa -desemejanza- restrictiva cuando hablamos del Dios entendido como Actualidad. Así, aunque todo acceso a Dios viene dado por el ser (lo divino) -como así queda ejemplificado para nuestro autor en las pruebas de la existencia de Dios, cuya esencia radica en la experiencia del ser40-, solo volviendo al misterio último del ser como mediación entre Dios y hombre (fe y razón), podrá este llevar su razón a la plenitud, beber de la anhelada fuente de Vida ${ }^{41}$. Queda de esta manera marcada la vía para un replanteamiento del problema de la analogía y el alcance del discurso sobre Dios.

\section{Estética, cristología y analogía}

La problemática de la unidad y diversidad del ser no debería constituir un mero eslabón dentro de una reflexión filosófica que por tal se tenga, ya que afecta al corazón mismo del desarrollo de la metafísica: el método ${ }^{42}$. Ya Aristóteles manifestó las diferentes maneras de decirlo, las cuales, si bien divergentes, decían todas algo con propiedad de él. ¿Cómo congeniar que lo real sea diverso, y por tanto equívoco, con la necesidad de que haya algo unívoco que lo unifique, pues podemos referirnos a ello y compararlo?

La historia de las ideas nos ha legado fundamentalmente dos alternativas: la analogía de atribución, por la cual una propiedad del ente se dice por referencia a un primero máximo (ej: 'a' y 'aa' se dicen en función de 'A'), de ascendencia platónica; y la analogía de proporcionalidad, en la cual las propiedades del ente se dicen por un análogo, trascendental, que expresa una proporción de proporciones (ej: $2 / 4$ se dice en relación de 3/6 en virtud de una 'relación de relación', que para el caso se puede expresar como "el denominador debe doblar al numerador", de forma que 6/12 también sería proporcionalmente análogo). Al respecto, es conocida la disputa tardo-medieval entre suaristas y cayetanistas en defensa de la supremacía de cada una de ellas. Una polémica que atañe no solo a una peculiar manera de concebir la analogía sino, sobretodo, a una ontología fundamental del ser.

¿Y von Balthasar, por cuál se inclina? Pues hablando con propiedad, por ninguna de las dos, aunque si acaso hay elementos de su propuesta que parecen tender

\footnotetext{
40 Pérez Haro, E., El misterio del ser.., op. cit., pp. 193-208.

41 Coll, J. M., "Hans Urs von Balthasar", op. cit., pp. 291-292

42 "Etant donné la place que tient l'analogie de l'être en métaphysique, chaque doctrine de l'analogie traduit une certaine conception de l'être, de la causalité, de la participation, de l'unité des êtres dans l'être" [Montagnes, B., La doctrine de l'analogie de l'être d'après Saint Thomas d'Aquin, Paris, Cerf, $2008^{2}$ (1963), p. 12]. Cf. Siewerth, G., Die Analogie des Seienden, Einsiedeln, Johannes Verlag, 1965 , p. 41.
} 
más a la proporcionalidad "intrínseca"43. Con tal de intentar dar una visión global de su planteamiento y explicitar esta matización, acudiremos a su ilustrativo texto "Revelación y belleza"44, editado en su totalidad en 1960 (parcialmente ya había aparecido en 1959), año inmediatamente anterior a la publicación del primer tomo de su Herrlichkeit, e integrado en su Skizzen zur Theologie, un volumen dedicado a la reflexión fundamental sobre la metodología teológico-filosófica ${ }^{45}$.

En el texto, aborda von Balthasar la específica cuestión de la belleza como expresión estética del ser, que, ante todo, no debe perder de vista que "solamente" es una parte de dicha expresión (los trascendentales, recordemos) 46 . Por ello, todo presunto entusiasmo por lo bello no puede estar desligado del imperativo ético de bondad revolucionaria (léase conversión) ${ }^{47}$, de modo que a todo acto contemplativo y de "fe" debe seguirle otro de índole activa (experiencia) ${ }^{48}$. La asunción de la perspectiva de los trascendentales implica reconocer una relación integral entre ellos y que, por tanto, se co-implican. Dado que para von Balthasar lo que le falta a la 'hora actual' es “acción donativa” (ágape), cualquier incursión en un mero espiritualismo escatológico entregaría irremediablemente el cosmos a los 'poderes'49, lo que a su juicio rebajaría sobremanera el valor último de la "creación". Para von Balthasar la "creación" es "para Dios la incoación de su autoentrega a las criaturas", de manera que "el ser creado en cuanto tal conserva el carácter de lo incoativo" 50 , y en especial los trascendentales en su totalidad. Por eso, lo verdaderamente bello nos consuela 51 .

Por lo dicho, podría parecer que el esquema balthasariano reproduce el esquema típico de la atribución intrínseca, esto es, que las criaturas participan por imita-

43 'La philosophie distingue principalement deux types d'analogie: l'analogie d'attribution et l'analogie de propotionnalité. Il appraîtra que seule cette dernière présente des traïts communs avec la conception que Balthasar se fait de l'analogie" (Cf. De Schrijver, G., Le merveilleux accord de l'homme et de Dieu. Étude de l'analogie de l'être chez Hans Urs von Balthasar, Lovaine, Leuven University Press-Peeters, 1983, p. 52).

44 Verbum Caro. Skizzen zur Theologie I, Einsiedeln, Johannes Verlag, 1960 (traducción castellana: Verbum Caro. Ensayos teológicos I, Madrid, Ed. Cristiandad, 1964).

45 Henrici, Peter, „Zur Philosophie Hans Urs von Balthasars”, en Lehmann, K., y Kasper, W., (eds.), Hans Urs von Balthasar. Gestalt und Werk, Köln, Communio, 1989, p. 241.

46 "La luz de los trascendentales -lo uno, lo verdadero, lo bueno y lo bello-, que se identifica con la luz de la filosofía, solo puede brillar si permanece integras". Cf. "Revelación y belleza", en Verbum Caro, op cit., p. 143 (orig.: „Das Licht der Transzendentalien - des Einen, Wahren, Guten und Schönen-, das eins ist mit dem Licht der Philosophie, kann nur scheinen, wenn es ungeteilt bleibt", Offenbarung und Schönheit, Verbum Caro, op. cit., p. 114).

47 Ídem.

48 Ibíd., p. 146 (orig.: Ibíd., p. 116).

49 Ibíd., p. 147 (orig.: Ibíd., p. 117).

50 Ibíd., p. 148 (orig.: ,für Gott die Inchoation seiner Selbsthingabe an die Geschöpfe sein sollte, behält das geschöpfliche Sein als solches den Charakter den Inchoativen”, Ibíd., p. 118).

51 Ídem. 
ción del primer analogado, "Dios", tanto a nivel existencial como predicamental (perfecciones del esse) 52 . Sin embargo, lo bello nos consuela, sí, pero "sin darnos (...) más que un sabor previo de todo ello, una indicación que apunta hacia la plenitud 'totalmente otra'" 53 , de ahí la presencia de la proporcionalidad. Asimismo, la referencia a este Totalmente Otro nos conduce, sin duda, al teólogo protestante Karl Barth. Y de hecho hay que recordar que von Balthasar dedicó a este referente de la teología del siglo XX una especial atención, concretada en 1951 en forma de libro54. La provocativa afirmación de Barth de que la analogia entis, en tanto que invención del Anticristo, era motivo suficiente para no devenir jamás católico55, obligó a muchos intelectuales católicos a repensar el modelo de la analogía y a proponer una propuesta que superase tal crítica ${ }^{56}$. Von Balthasar celebró y asumió la analogía fidei, que era la contrapropuesta de Barth a la analogia entis, aunque no precisamente en 'contra' de esta, sino más bien 'in' puesta por esta. Es decir, si bien reconocía con Barth que a la "encarnación de la palabra divina" hay que ponerla como el universal concreto del que todo parte y al que todo fluye, quiso asimismo evitar la unilateralidad de Barth en lo referente a la doctrina de la predestinación, proponiendo una dialéctica de libertad-responsabilidad humana y "gracia" divina que reconociera también el papel fundamental de la "creación" y la Alianza divina ${ }^{57}$. De este modo la analogia fidei quedaba incluida en la analogia entis, que para von Balthasar constituye en última instancia la misma analogia theologica58 esgrimida por Barth en contra de Przywara. Es decir, que si bien esa plenitud última es el Totalmente Otro, esta "no se encuentra lejos sino que está ya presente”: "¡Entre vosotros hay uno a quien no conocéis!" 59 , por eso la cuestión del ser, a través del

52 Según la doble modalidad que propone Cornelio Fabro (Partecipazione e causalità secondo $S$. Tommaso d'Aquino, Torino, Società Editrice Internazionale, 1960, pp. 323-466).

53 V. Balthasar, “Revelación y belleza”, en Verbum Caro, op. cit., p. 148 (orig.: „ohne uns davon mehr zu geben als einen Vorgeschmack, einen Hinweis auf die nicht ferne, sondern schon gegenwärtige, 'ganz andere' Erfüllung”, Offenbarung und Schönheit, Verbum Caro, op. cit., p. 118-119).

${ }^{54}$ Karl Barth. Darstellung und Deutung seiner Theologie, Köln, Jakob Hegner, 1951; Pannenberg, W., „Zur Bedeutung des Analogiegedankens bei Karl Barth. Eine Auseinandersetzung mit Urs von Balthasar", Theologische Literaturzeitung, 78 (1953), pp. 17-24.

55 „Ich halte die analogia entis für die Erfindung des Antichrist und denke, dass man ihretwegen nicht katholisch werden kann”, KD I/1, Chr. Kaiser, München, 1932, p. VIII.

56 Célebre es al respecto el proyecto de Erich Przywara, concretado en su Analogia Entis. Metaphysik. Ur-struktur und All-rhythmus, Einsiedeln, Johannes Verlag, 1962 (esta edición incorpora y completa la primera, de 1932, con diversos escritos que vienen a constituir, si bien fragmentariamente, una suerte de segunda parte de la misma).

57 Moda, Aldo, Hans Urs von Balthasar, Bari, Ecumenica Editrice, 1976, pp. 130-137; De Schrijver, G., Le merveilleux accord de l'homme et de Dieu, op. cit., pp. 183-184 y pp. 288-296.

58 V. Balthasar, Karl Barth, op. cit., pp. 267-273.

59 V. Balthasar, “Revelación y belleza”, en Verbum Caro, op cit., p. 148 (orig.: „Unter euch steht einer, den ihr nicht kennt!", Offenbarung und Schönheit, Verbum Caro, op. cit., p. 119). 
trascendental de la belleza, nos lleva en última instancia al verdadero "análogo trascendental", a la cristología60.

El "hecho de que la Palabra se hiciese carne, constituye siempre, en cuanto exceso, juntamente con la promesa, una forma, y por ello ha de exigirse necesariamente también la unidad humano-divina como forma, más aún, como forma de las formas", asume von Balthasar61. Se co-significa de este modo que Dios se proporciona cristológicamente como manifestación de la misma proporción trinitaria, dejando resonar su propia voz a través de la voz humana. De este modo, "Cristo", que es la creación artística central de Dios, es tanto expresión de la divinidad como absoluta y perfecta manifestación humana ${ }^{62}$. Solo desde esta confluencia se puede para von Balthasar hablar de una cierta analogía con Dios ${ }^{63}$, pues su libre 'proporción' a lo humano nos ayuda a reconocer el fundamento último del ser: el "ágape". "El contenido de esta forma es el ágape del Padre"64, de forma que, de "repente solo una cosa es ya esencial: el amor. Pero de su monismo vuelven a brotar siempre nuevas todas las cosas: la sencilla riqueza del ser único se despliega en la plenitud trinitaria, cristológica, eclesiológica, sacramental y cosmológica"65. La filosofía del ser solo se completa con una filosofía del amor66, una apertura que se conjuga con que Dios sea siempre exceso (Deus semper maior), y que en última instancia sea reconocido como misteriosa tiniebla luminosa 67.

Esta revelación concreta y universal, humana y divina, entra dentro del mismo proceso revelador de Dios. Dios decidió que no quería ser sin el mundo68, por eso

60 La relación entre esta teoría de la analogía y una teología trinitaria de Dios se revela así como una relación íntima e inter-cambiable. De hecho, para von Balthasar solo desde este esquema analógico puede esgrimirse una teología trinitaria sólida y relevante. Luciani Rivero, Rafael Francisco, El misterio de la diferencia, op.cit., pp. 457-542 (capítulo IX. "La Palabra de Dios hecha carne").

61 V. Balthasar, "Revelación y belleza”, en Verbum Caro, op. cit., p. 156 (orig.: „,der Tatsache, dass das Wort Fleisch geworden ist, als Überschwang mit der Verheissung zusammen noch immer eine Form bildet und deshalb auch die gottmenschliche Einheit als Form, ja als die Form aller Formen angeschprochen werden muss", Offenbarung und Schönheit, Verbum Caro, op. cit., p. 125).

62 Ibíd., p. 155 (orig.: Ibíd., pp. 124-125).

63 "L'evento di Gesú Cristo realizza l'analogia entis al massimo grado possibile" (Scola, A., Hans Urs von Balthasar..., op. cit., p. 71).

64 V. Balthasar, “Revelación y belleza”, en Verbum Caro, op. cit., p. 162 (orig.: „Der Inhalt dieser Form ist die uns geschenkte Agape des Vaters", Offenbarung und Schönheit, Verbum Caro, op. cit., p. 130).

65 Ibíd., p. 158 (orig.: ,plötzlich ist nur noch eins wesentlich, die Liebe. Aber aus ihrem Monismus entspringt je wieder alles neu: der einfältige Reichtum des einen Seins legt sich auseinander in die trinitarische, die christologische, ekklesiologische, sakramentale und kosmologische Fülle”, Ibíd., p. 127).

66 Henrici, Peter, „Zur Philosophie Hans Urs von Balthasars”, art. cit, p. 258.

67 Ide, P., Etre et Mystère ..., op. cit., 1995, pp. 138. Cf. Henrici, Peter, „Zur Philosophie Hans Urs von Balthasars", art. cit., p. 255.

68 Von Balthasar, "Revelación y belleza", en Verbum Caro, op. cit., p. 159 (orig.: Offenbarung und Schönheit, Verbum Caro, op. cit., p. 128). 
la "Revelación" de Dios no destituye con el misterio de la "cruz" la revelación misma del ser (estética) -aunque tampoco la sustituye, puntualiza. La visión bella de este acontecimiento se hace dentro del mismo proceso de "Revelación" histórica, por eso no puede agotar lo divino69. Pero sí es de algún modo superlativa e insustituible porque, entre otras cosas, invita suficientemente a la plena participación en el misterio del 'ser' y sus trascendentales, y a una plena asunción de su acción en el mundo, esto es, a una obligada participación "de manera insondable" en la pasión 70 . Porque no es posible ser solo contempladores de la forma de Dios, sino que ello nos empuja a convertirnos en sus colaboradores, y por lo tanto, actores de ella, dice 71 . Si en la "Encarnación" está la respuesta al misterio del ser, lo es de todo el ser, de todas sus regiones, también la ética, entendida como dramático acontecer de la humanidad en el mundo, presa de la dialéctica y tensa relación de lo finito y lo infinito (Theodramatik) 72 .

\section{La aportación balthasariana: acotaciones para una reflexión}

La metafísica de von Balthasar está impregnada de una particular energía filosófica y espiritual. No cabe duda de que su lectura no puede dejar indiferente a quien se entregue a ella, tanto por la vastedad erudita de los datos, documentos y figuras que atiende, como por el profundo alcance que sus proposiciones pretenden. Darse cuenta de esta magnitud es reflejo de una constatación fundante: su propuesta es un intento de respuesta al misterio de la vida, con sus resortes y sus agonías, a partir de su convicción cristiana, un prisma por el cual hace pasar todas las cuestiones "mundanas". Huelga decir que comprender la confección de todo el entramado de preguntas y respuestas implica desplegar con gran detenimiento sus posiciones, y así extenderse a otros aspectos capitales de su propuesta teológica, so pena de condenar todo ensayo hermenéutico a la parcialidad e inexactitud. Sin embargo, a partir de lo dicho algunas cuestiones que atañen a la metafísica y a su posibilidad quedan puestas sobre la mesa con suficiente claridad y meridiana implicación ontológica, y por eso a ellas nos queremos ahora a referir.

Se comprende claramente el sentido de querer separar el ser de Dios; de lo contrario habría una reducción panteísta final en que todo sería de algún modo Dios, una tesis poco congeniable con el tradicional dogma cristiano de la sobrenaturalidad de Dios. Se trata de mantener la inmanencia, sí, pero también la trascendencia

\footnotetext{
69 Ibíd., pp.151-152 (orig.: Ibíd., pp. 121-122).

70 Ibíd., p. 150 (orig.: Ibíd., p. 120).

71 Albus, M., Die Wahrheit ist Liebe, op. cit., p. 32.

72 „Weil das Sein Liebe ist, deshalb steht im Zentrum der Triologie nicht die Ästhetik, sondern die Dramatik” (Cf. Henrici, Peter, „Zur Philosophie Hans Urs von Balthasars”, art. cit., p. 259).
} 
de un Absoluto que se afirma más allá de la concreción de los entes. Y la sugerencia del esse como mediación parece superar este dilema y articular un puente que uniría, en su des-semejanza, el mundo con Dios. Se entiende asimismo que la contingencia del ente, que implica una pregunta fundacional, se resuelva desde una perspectiva teísta por la dependencia causal (ergo diferencial) de lo Necesario, de modo que su propio fundamento no reside en otro lugar que en esa relación ${ }^{73}$. Una relación de real necesidad que desde esta perspectiva ni apaga la autonomía de lo finito y su libertad, ni eclipsa la responsabilidad de acción nacida de su estatuto onto-práctico. Porque, en efecto, parece que el panteísmo conduce irremediablemente al monismo substancial, y con ello a la erradicación de toda libertad finita (Spinoza).

No obstante, si ser y ente guardan mutua necesidad, de modo que fundamento y manifestación son inseparables ${ }^{74}$, ¿se "da" (es gibt) el ser al tiempo que lo hace el ente? O dicho de otro modo: el ser, como tal, no puede ser contingente, y en caso de que lo fuera vendría dado por otro ser anterior, pues la estructura contingente que pone la pregunta sería la misma. Pero si el ser no se da inseparablemente del ente, parece que solo podríamos solventar la problemática situando el 'ser sin el ente' en otro "depósito", en este caso, 'Dios'. Sin embargo, esta eventual "solución" nos conduciría a cuestiones no menos aporéticas: ¿Qué es entonces "Dios", también un ente (Suárez)? ¿Y qué diferenciaría a este ente de ser una sustantivación subsistente del ser? ¿Qué relación existiría entre Dios y el ser si, además, tal 'ser' no es un concepto unívoco, una abstractio de la dualidad de seres ontológicos (ser-divino; ser-mediación) de lo real? Por todo ello, el ser-mediación tiene que estar ya de algún modo en Dios, a menos que no establezcamos una diferencia ontológica entre ellos que, por ende, nos remitiría a la necesidad de justificar la presencia de dicho 'ser' en un contenido que no lo tiene por esencia (participatio).

El 'ser' no es generado, sino emanado, luego ya está en Dios, se podrá decir. Pero en el fondo esta respuesta no resuelve la problemática, ya que aplaza el cuestionamiento de la relación entre subsistencia y ser, por lo que se podría contra-objetar preguntando sobre la relación que hay entre el ser subsistente y el ser no-subsistente. Y es que, y ahí está el núcleo de la cuestión: ¿estamos hablando de una misma "cosa" con modulación diferente?

Para von Balthasar este ser no es un segundo 'dios', aunque sí se lo podría 'entender' como lo divino, como el flujo absoluto, según hemos dicho. De algún modo hay pues una estrecha relación entre ambos, una semejanza, que no identificación. Pero con ello podría pensarse que el ser actualiza a Dios, de manera que

\footnotetext{
73 Fabro, C., Esegesi Tomistica, Roma, Libreria Editrice della Pontificia Università Lateranense, 1969, p. 68.

74 V. Balthasar, Theologik. Zweiter Band: Wahrheit Gottes, Einsiedeln, Johannes Verlag, 1985, pp. 166ss. Cf. Pérez Haro, E., El misterio del ser..., op. cit., p. 154.
} 
Este sería "relativo a...", una posibilidad que queda descartada por ser Dios el Ipsum Esse Subsistens, clásica glosa tomasiana del "nombre de Dios", fundamento del cual no hay nada "más allá".

Solamente cabe mantener que el ser y Dios mantienen una estrecha relación de unidad en la desemejanza ontológica más radical; esto es, una relación de 'unidiversidad'. En otras palabras: las "divinidades" participan de lo "divino", por eso es lo divino el punto último de referencia y la forma una concreción de ello. Unos verán (los más teo-lógicos) una vía para dar expresión a algunos dogmas clásicos del cristianismo; otros (los más onto-lógicos) reconocerán en ello la vía para reclamar una lectura más simbólica y apofática del discurso sobre los "Dios"75, pero no la relación entre hipóstasis divina, concreta y diferente (ente), y esencia común, o "divinidad" (ser).

Vemos, pues, que el ser como mediación solventa, desde una perspectiva cristiano-teísta, el problema del panteísmo, pero asimismo convoca a resolver cuestiones relativas a su inicio y valor original en el orden existencial, y más todavía cuando vemos que está tan intrínsecamente relacionado con lo ente, con lo finito, con lo temporal. De ahí que se intuya una cohabitación problemática con "Dios". Porque si para solventar la aporía se acude a la doctrina de la Trinidad, es decir, al primado de analogia fidei y la "Revelación" para encarar los dilemas de la analogia entis,

\footnotetext{
75 Jean-Luc Marion nos ofrece una versión más actual del debate entre el "dios" vivo y el "dios" de los sabios en su reconocido Dieu sans l'être (1982; aquí la citaremos según la primera edición en Presses Universitaires de France, de 1991), libro en el que incide en la necesidad de diferenciar entre lo "idolátrico" y lo "icónico". Toda proyección metafísica de lo divino incurre en lo "idolátrico", en la "visión" en función de quién lo ve, el hombre, por eso la concepción de "Dios" deviene un concepto límite, una asíntota última del Da-sein que pregunta sobre la "causa" del mundo (pp. 51-58). Por el contrario, el "icono" no produce una determinada visión, sino que la con-voca y luego la in-voca. Cualquier parecido nunca puede agotar aquello a lo se refiere, pues el "invisible" es irreductible a cualquier visión, de modo que el icono obliga al hombre a perderse en lo invisible que entrecortadamente se deja ver, por decirlo de algún modo (pp. 28-32), comportando así que el icono, como tal, asuma aquello a lo que se refiere como 'diferencia', como profundidad sin fin y saturación (pp. 35-36).

Para Marion, pensar a Dios es una imposibilidad que está condenada a la idolatría, inclusive aquella que, como la Heidegger, pretende encontrar algo de lo divino en la escucha del ser. Remitir la meditación sobre lo divino al pensar del ser es incurrir en un nuevo proceso de idolatría (pp. 70ss.) porque se 'pone' lo divino en la perspectiva del ser. Solamente el amor, el ágape, puede ofrecer un pensar sobre lo divino sin idolatría. ¿Por qué? "Dieu ne peut se donner à penser sans idolâtrie qu'à partir de lui seul: se donner à penser comme amour, donc comme don; se donner à penser comme une pensée $d u$ don" (p. 75). Para Marion es la cristología, y más concretamente la eucaristía, la que da forma a esa vivencia del ágape, a esa convocatoria icónica de lo divino (pp. 197ss.).

Con todo, y según lo que venimos diciendo, nos topamos de nuevo la aporía de la analogia fidei/entis. Sin embargo, la unilateralidad de esta última afirmación y su más que problemática "fenomenicidad" metodológica no empaña, a nuestro juicio, la profundidad y precisión de las afirmaciones de Marion por cuanto se refiere al destino idolátrico del pensar metafísico. Eso sí, queda por dilucidar si hablar sobre lo divino y de este secreto con tanta prolijidad no supone una nueva incursión en la trascendentalización (en este caso del ágape) del discurso sobre lo apofático y el misterio del ser.
} 
entonces la reflexión se subyuga a una arbitrariedad problemática, a través de la cual, con todo, siguen vigentes cuestiones que gravan profundamente la no-identidad entre el ser y Dios. Pensemos por ejemplo en la relación temporal entre ambas "categorías" (Dios y el ser), la causalidad ontológica y óntica respectivas y, como corolario, la entidad meta-física de cada una.

En este mismo sentido, parece que la analogía, pivotada en última instancia en la unidad-dual de la forma "Cristo" (hombre-Dios), entendida como forma de las formas de Dios, sería en su fondo una variación más de la analogia fidei barthiana, si se quiere enriquecida por la analogia entis a posteriori y siempre releída a partir de aquella, ya que recibe su legitimación última e insondable de la "sagrada escritura"76. La razón humana sería entonces algo así como el náufrago que es rescatado por un barco aparecido milagrosamente entre el oleaje.

Sí es cierto, por otro lado, que la originalidad de la comprensión de la dinámica del ser77 como emanación de Dios es un aspecto poco encontrado en las interpretaciones hechas sobre la obra tomasiana. Von Balthasar, que siempre se reconoció como tomista78, buscó para todas sus afirmaciones el apoyo de los textos del Aquinate. Ciertamente dice Tomás "emanatio totius entis a causa universali"79, para lo cual se entiende que creatio es la emanación de todo ser 80 (conviene anotar que en este pasaje von Balthasar no lo cita afirmando totius entis, sino totius esse,

\footnotetext{
76 Por contra, para aquel que acepte el primado de la "Revelación" y abandone el menos agradecido terreno de la "mera razón", la cuestión del ser así planteada abrirá nuevas posibilidades para una metafísica del amor y de la consideración donal del propio ser, pues precisamente en tanto que 'amor' que se contituye como base para una metafísica última de corte personalista, se abre la posibilidad ontológica del 'reconocimiento'. Nos referimos sobre todo al itinerario que ha seguido Ferdinand Ulrich (1931), quien desde la asunción de la diferencia del ser desarrolla una metafísica del amor y de la persona que se corona útlimamente en la afirmación de la diferencia en la misma divinidad. Se trata de un pensamiento amibicioso en el planteamiento de una 'nueva metafísica' del ser que se enriquece del diálogo que el autor emprende con la filosofía de la modernidad tardía (Kierkegaard, Marx, Hegel,...). [Ulrich, F., Schriften I-V, Johannes-Verlag Einsiedeln 1998-2006, en especial el quinto volumen (Band V. Gabe und Vergebung. Ein Beitrag zur biblischen Ontologie), en la que ensaya una reflexión ontológica del 'don y el perdón' en base a la parábola del hijo pródigo ( $L c 15,11-32)]$. Para una comprensión de conjunto de la discusión con la filosofía de la modernidad, ver la obra de Stefan Oster, Mit- Mensch-Sein. Phänomenologie und Ontologie der Gabe bei Ferdinand Ulrich (FreiburgMünchen, Karl Aber, 2004).

Por útlimo, para un contextualización global y desarrollo de las problemáticas que arrancan de los planteamientos de Siewerth y von Balthasar, véanse Martin Bieler, "The Future of the Philosophy of Being", Communio International Catholic Review, 26, no. 3 (1999), pp. 455-485, "Causality and Freedom", Communio International Catholic Review , 32, no. 3 (2005), pp. 407-434, y sobre todo la magna Freiheit als Gabe. Ein schöpfungstheologischer Entwurf ya citada.

77 "The philosophy of being is dynamic", dice Bieler ("The future of the...", art. cit., p. 461).

78 Henrici, Peter, „Zur Philosophie Hans Urs von Balthasars”, art. cit., p. 253

79 Summa Theologiae I, 45,1

${ }^{80}$ Así se manifiesta J.B. Lotz (Transzendentale Erfahrung, Freiburg, Herder, 1978, pp. 153-154).
} 
queriendo quizás "encontrar" en el texto tomasiano elementos que coincidieran con su personal interpretación...81). Pero asimismo debemos afirmar categóricamente que dicha creatio no es una mutatio, y que como tal se distingue de cualquier modo de producción 82 . Solo desde esta acotación, podemos decir que todo el ser "emana" de su causa primera, "Dios", y que esto recibe el nombre de "creación", cuya esencia es la producción absoluta y radical del acto de existir y, por eso, es una potencia activa restringida a Dios ${ }^{83}$. Ahora bien, solo se crea lo que ya no es exactamente lo mismo, luego el ser y Dios no compartirían identidad ontológica, con lo cual esse comune e ipsum esse no coinciden ${ }^{84}$. Interpretada así la emanatio, aparece la diferencia como el fundamento ontológico para la explicitación plausible de un sistema metafísico que incorpora la diferencia divina y su vida interna. Pero eso, ya lo hemos dicho, comporta aporías de difícil solución metafísica que comprometen el mismo proyecto del cual nace y, en cualquier caso, el alcance de su eventual efectividad.

Con todo, situar la emanatio en la perspectiva de la diferencia intra-divina le permite a von Balthasar decir, citando literalmente al propio G. Siewerth, que "...la separación en Dios 'no puede ser esencialmente otra cosa que relación absoluta'. Apoyándose en esta afirmación, G. Siewerth intentará deducir 'especulativamente todas las diferencias solo de la distinción real de subsistencia divina', e 'iluminar[las] tanto en su múltiple nulidad como en su estructura mediadora (...) 'A través del desposeimiento, la potencia, la alteridad, el no ser, el cambio, domina lo positivo de un movimiento infinito del ser hacia la realidad, que como tal no procede de la forma, sino que acontece en lo íntimo del ser mismo. Así, solo esto es la pura parábola del absoluto. ,"85

81 V. Balthasar, Gloria. Vol 4, op. cit., p. 360, nota 40 (orig.: Herrlichkeit, op. cit., p. 361). La viabilidad de interpretar el intento de G. Siewerth como una fundamentación ontológica del esse commune en tanto que 'mediato' es para J. De Vries ["Das 'esse commune' bei Thomas von Aquin", en Scholastik, 39 (1964)] más que problemática y en cualquier caso no viabiliza hablar de una con-creación o emanación del esse (commune) en el Aquinate. En este sentido como señala John F. Wippel, Tomás también sostiene que el "esse commune does not exist as such apart from individual existents, except in the order of thought" (The Metaphysical Thought of Thomas Aquinas. From Finite Being to Uncreated Being, Washington, The Catholic University of America Press, 2000, p. 121).

82 Lotz, J.B., Transzendentale Erfahrung, op. cit., pp. 153-154).

83 Gilson, E., El Tomismo, Pamplona, EUNSA, $2000^{3}$, pp. 201-205.

${ }^{84}$ Lotz, J.B., Die Transzendentale Erfahrung, op. cit., p. 155.

85 V. Balthasar, Teológica, 2. Verdad de Dios, Madrid, Encuentro, 1997, p. 180 (orig.: ,somit kann die Scheidung in Gott 'wesenhaft nichts als absolute Relation sein'. G. Siewerth wird aufgrund dieser Feststellung versuchen, 'alle Differenzen nur aus dem realen Unterschied der göttlichen Subsistenz spekulativ' herzuleiten und jene 'in ihrer vielfältigen Nichtigkeit wie in ihrer vermittelnden Struktur zu erhelen' (...) Durch die Entäusserung, die Potenz, die Anderscheit, das Nichtsein, die Veränderung hindurch waltet das Positive einer unendlichen Bewegung des Seins zur Realität, die als solche nicht aus der Form her kommt, sondern im Innern des Seins selbst sich ereignet. So erst ist dieses das reine Gleichnis des Absoluten", Theologik. Zweiter Band: Wahrheit Gottes, op. cit., pp. 169-170). 
Si en toda la obra de von Balthasar hallamos como constante telón de fondo la referencia a la belleza y a la estética como categorías para un discurso sobre Dios es porque el recurso al arte, su alteridad, la genialidad de su dación, la originalidad de su contenido, etc., se presentan como formas de expresión simbólica sugerente para la pregunta metafísica. No en vano la teoría romántica del arte podría suscribir sin titubeo estas relaciones. Pero a pesar de la vecindad existente entre ambas experiencias (la estética y la metafísica o existencial), que remiten sin duda a un arrebatamiento radical y a la transición a terrenos no conocidos a partir de lo cual se le abre al sujeto una dimensión que le trasciende y lo relativiza, la experiencia profunda de la contingencia, como semántica de "estar en el mundo" y la consiguiente pregunta por la viabilidad de la experiencia religiosa, reviste de una fuerza de impacto en la conciencias teoréticas y prácticas de quién las experimenta de talla única, y por eso podemos intuir que va más allá de la contemplación y vivencia de la fuerza sublime que constituye la experiencia estética86. Quizás por eso von Balthasar sostenga que "solo el corazón que conoce el arte de Dios puede intentar ordenar con una nueva medida la preponderancia de la confusión en nuestra época" 87 . Aunque no queda claro que sea precisamente su meta-física la que más luz arroje a nuestra hora.

Terminamos. Como glosa final podemos decir que, en virtud de una interpretación nada ontológica (y por ende nada balthasariana) de ese "Dios", asumimos que tal confín, simbólico, una vez despojado de toda ilusión onto(teo)lógica racionalista y a priori teológico meta-epistemológico (el cual, además, ¿por qué debería ser precisamente 'teológico' y no 'positivista' o 'trascendental', por ejemplo? ¿y por qué cristiano, y además católico?) se asienta en última instancia en lo primario como lo últimamente indudable: el pasmo del ser-en-el-mundo, de la efectividad propia, tan familiar como extraña, recibida sin más 88 , y convertida en tarea metafísica y en arte de convivencia en la contingencia. Un quehacer que nos apela a cada uno de nosotros y que ninguna filosofía puede renunciar a ello y que en algún momento debe habérselas con su horizonte "ab-soluto" (sea de la índole que sea). Un tema que se da en las entrañas mismas de la experiencia del pensamiento y que, por ende, debe acotarse a la experiencia de la razón y sus condicionamientos, tan

\footnotetext{
86 Puede verse un breve pero fecundo desarrollo de esta cuestión en Blanch, A., "Comparación de la experiencia estética con la religiosa”, en Dou, A. (ed.), Experiencia Religiosa, Madrid, UPCO, 1989, pp. 83-90.

87 V. Balthasar, Verbum Caro, “Revelación y belleza”, op. cit., p. 166 (orig.: „Nur das um Gottes Kunst wissende Herz kann es sich zumuten, das Unmass an Wirrnis unserer Zeit in neue Masse zu ordnen", Offenbarung und Schönheit, Verbum Caro, op. cit., p. 134).

88 Parece ineludible no nombrar aquí a J. L. Marion y sus múltiples ensayos al respecto, de los cuales quisiéramos destacar, para lo que nos compete, Étant donné (Paris, PUF, 1997) y Le phénomène érotique (Paris, Grasset, 2003). Asimismo, y para una lectura de la obra de Marion desde una perspectiva del amor y el eros, véase Caecus Amor. Jean-Luc Marion e la dismisura del fenomeno, de Rosaria Caldarone (Pisa, Edizioni ETS, 2007). Cf. Supra, nota 75.
} 
plurales como, seguramente, insoldables. La cuestión está y estará ahí. Y no valen las opciones extremas ni resoluciones tajantes, ya sea para descalificarla por aracional o para reducirla a un solo discurso en virtud de un "evidente" a priori teológico. Como diría Karl Jaspers, es el desencuentro entre la "fe filosófica" frente a la fe en la "Revelación" el que atraviesa el planteamiento de estas cuestiones, y cada uno de nosotros debe afrontarlo. Porque estas preguntas, tan sencillas como profundas, tarde o temprano (re)aparecen.

\section{Referencias bibliográficas}

Albus, M., Die Wahrheit ist Liebe. Zur Unterscheidung des Christlichen nach Hans Urs von Balthasar, Freiburg-Basel-Wien, Herder, 1976.

BIELER, M., "Causality and Freedom", Communio International Catholic Review, $32 / 3(2005)$.

Bieler, M., "The Future of the Philosophy of Being", Communio International Catholic Review, 26/3 (1999).

Blanch, A., "Comparación de la experiencia estética con la religiosa", en Dou, A (ed), Experiencia Religiosa, Madrid, UPCO, 1989.

Coll, J.M., "Hans Urs von Balthasar (1905-1988)", en Lluís Font, P. (ed.), 10 pensadors cristians del s. XX, Barcelona, Ed. Cruilla, 1999.

De Schrijver, G., Le merveilleux accord de l'homme et de Dieu. Étude de l'analogie de l'être chez Hans Urs von Balthasar, Lovaine, Leuven University PressPeeters, 1983.

Fabro, C., Esegesi Tomistica, Roma, Libreria Editrice della Pontificia Università Lateranense, 1969.

FABro, C. Partecipazione e causalità secondo S. Tommaso d'Aquino, Torino, Società Editrice Internazionale, 1960.

GilBert, P., "L'articulation des transcendantaux selon Hans Urs von Balthasar", Revue Thomiste, 86 (1986).

Gilson, E., El Tomismo, Pamplona, EUNSA, $2000^{3}$.

Henrici, P, „Zur Philosophie Hans Urs von Balthasars”, en Lehmann, K., y Kasper,

W., (eds.), Hans Urs von Balthasar. Gestalt und Werk, Köln, Communio, 1989.

IDE, P., Etre et Mystère. La philosophie de Hans Urs von Balthasar, Bruxelles, Culture et Vérité, 1995.

JASPERS, K., Der philosophische Glaube angesichts der Offenbarung, München, Piper V., 1962.

Lotz, J.B., Transzendentale Erfahrung, Freiburg, Herder,1978.

LUCIANI RIVERo, R. F., El misterio de la diferencia : un estudio tipológico de la analogía como estructura originaria de la realidad en Tomás de Aquino, Erich Przywara y Hans Urs von Balthasar y su uso en teología trinitaria, Roma, PUG, 2002.

MARIOn, J.L., Dieu sans l'être, Paris, PUF, 1982. 
Marion, J.L., Étant donné, Paris, PUF, 1997.

ModA, A., Hans Urs von Balthasar, Bari, Ecumenica Editrice, 1976.

Montagnes, B., La doctrine de l'analogie de l'être d'après Saint Thomas d'Aquin, Paris, Cerf, $2008^{2}$.

PannenberG, W., „Zur Bedeutung des Analogiegedankens bei Karl Barth. Eine Auseinandersetzung mit Urs von Balthasar", Theologische Literaturzeitung, 78 (1953).

PÉrez Haro, E., El misterio del ser. Una mediación entre Filosofía y Teología en Hans Urs von Balthasar, Barcelona, Santandreu Ed., 1994.

ScolA, A., Hans Urs von Balthasar: Uno stile teologico, Milano, Jaca Book SpA, 1991.

SEguró, M., Los confines de la razón. Analogía y metafísica trascendental, Barcelona, Herder, 2013.

Siewerth, G., Das Sein als Gleichnis Gottes, Heidelberg, F. H. Kerle, 1958.

Siewerth, G., Die Analogie des Seienden, Einsiedeln, Johannes Verlag, 1965.

Von Balthasar, Hans Urs, Karl Barth. Darstellung und Deutung seiner Theologie, Köln, Jakob Hegner, 1951.

Von Balthasar, Hans Urs, Herrlichkeit: eine Theologische Ästhetik, Einsiedeln, Johannes Verlag, 1961-1969 (trad.: Gloria. Una estética teológica, Madrid, Ed. Encuentro, 7 vols.).

Von Balthasar, Hans Urs, Mein Werk. Durchblick, Einsiedeln, Johannes Verlag, 1990.

Von Balthasar, Hans Urs, Theodramatik, Einsiedeln, Johannes Verlag, 1973-1983 (traducción castellana: Teodramática, Madrid, Ed. Encuentro, 5 vols.).

Von Balthasar, Hans Urs, Theologik, Einsiedeln, Johannes Verlag, 1985-1987 (traducción castellana: Teológica, Madrid, Ed. Encuentro, 3 vols., además de un Epílogo que concluye todo el proyecto).

Von Balthasar, Hans Urs, Verbum Caro. Skizzen zur Theologie I, Einsiedeln, Johannes Verlag, 1960 (traducción castellana, Verbum Caro. Ensayos teológicos I, Madrid, Ed. Cristiandad, 1964).

Von Balthasar, Hans Urs, "Intento de resumir mi pensamiento", Communio, Revista Católica Internacional (ed. española), IV/88.

White, T. J. (ed.), The Analogy of Being. Invention of the Antichrist or the Wisdom of God?, Grand Rapids, Eerdmans, 2010.

WipPEL, J.F., The Metaphysical Thought of Thomas Aquinas. From Finite Being to Uncreated Being, Washington, The Catholic University of America Press, 2000.

Miquel Seguró

PSITIC

Universitat Ramon Llull

mseguro@rectorat.url.edu 